\title{
A GENERALIZATION OF DARBO'S FIXED POINT THEOREM AND LOCAL ATTRACTIVITY OF GENERALIZED NONLINEAR FUNCTIONAL INTEGRAL EQUATIONS
}

\author{
Bapurao C. Dhage, Shyam B. Dhage and Hemant K. Pathak
}

\begin{abstract}
We prove a generalization of a measure theoretic fixed point theorem of Darbo in Banach spaces which includes some well-known fixed point theorems of Dhage and Sadovskii as special cases. A generalized nonlinear functional integral equation is studied via Dhage fixed point theorem for attractivity of the solutions on unbounded intervals of real line. Finally the validity of our hypotheses imposed on the functional integral equation is also discussed with a numerical example.
\end{abstract}

Mathematics subject classification (2010): 34A60, 47H09, 47H10, 54H25.

Keywords and phrases: measure of noncompactness, Dhage fixed point theorem, functional integral equation, local attractivity of solutions.

\section{REFERENCES}

[1] R.P. Agarwal, J. Banas, B.C. Dhage, S.D. Sarkate, Attractivity results for a nonlinear functional integral equation, Georgian Math. J., 18 (2011), 1-19.

[2] R.P. Agarwal, J. BANAS, B.C. Dhage, T. Gnana Bhaskar, Local and global attractivity results for quadratic functional integral equations, Funct. Diff. Equ., 17 (2010), 3-19.

[3] A. Aghajani, J. Banas, N. Sabzali, Some generalizations of Darbo fixed point theorem and applications, Bull. Belg. Math. Soc. Simon Stevin, 20 (2013), 345-358.

[4] R.R. Akhmerov, M.I. Kamens kit, A.S. Potapov, A.E. Rodhina, B.N. Sadovs KiI, Measures of noncompactness and Condensing Operators , Birkhauser Verlag, 1992.

[5] J. BANAS, B.C. DHAGE, Global asymptotic stability of solutions of a functional integral equation, Nonlinear Anal., 69 (2008), 1945-1952.

[6] J. Banas, K. Goebel, Measures of Noncompactness in Banach Spaces, LNPAM Vol. 60, Marcel Dekker, New York 1980.

[7] G. DARBo, Punti uniti i transformazion a condominio non compatto, Rend. Sem. Math. Univ. Padova, 4 (1995), 84-92.

[8] K. Deimling, Ordinary Differential Equations in Banach Spaces, LNM Springer Verlag, 1977.

[9] B.C. DHAGE, A nonlinear alternative with applications to nonlinear perturbed differential equations, Nonlinear Studies, 13, (4) (2006), 343-354.

[10] B.C. DHAGE, Asymptotic stability of the solution of certain nonlinear functional integral equations via measures of noncompactness, Comm. Appl. Nonlinear Anal., 15, no. 2 (2008), 89-101.

[11] B.C. DHAGE, Attractivity and positivity results for nonlinear functional integral equations via measures of noncompactness, Differ. Equ. Appl., 2, (1) (2010), 299-318.

[12] B.C. DHAGE, Hybrid fixed point theorems with PPF dependence in Banach algbras with applications, J. Nonlinear Anal. \& Optim. 5(1) (2014), 37-48.

[13] B.C. Dhage, A.V. Deshmukh, J.R. Graef, On asymptotic behavior of a nonlinear functional integral equation, Comm. on Appl. Nonlinear Anal., 14 (2007), 1-12.

[14] B.C. DHAGE, V. LAKSHMikATHAM, On global existence and attractivity results for nonlinear functional integral equations, Nonlinear Analysis, 72 (2010), 2219-2227. 
[15] B.C. Dhage, S.K. Ntouyas, Existence results for nonlinear functional integral equations via a fixed point theorem of Krasnoselskii-Schaefer type, Nonlinear Studies 9 (3) (2002), 307-317.

[16] B.C. Dhage, S.K. NTOUYAs, Existence of positive monotonic solutions of functional hybrid fractional integral equations of quadratic type, Fixed Point Theory, 16 (2015), (In press).

[17] B.C. Dhage, S.B. Dhage, S.K. NTOUYAs, H.K. PATHaK, On local attractivity of nonlinear functional integral equations via measures of noncompactness, Malaya J. Mat., 3 (2015), (to appear).

[18] M.A. KRASNOSELSKII, Topological Methods in The Theory of Nonlinear Integral Equations, Pergamon Press, New York, 1964.

[19] K. KuRatows KI, Sur les espaces complets, Fund. Math., 5 (1930), 301-309.

[20] B.N. SADOvSKII, Limit-compact and condensing operators, Russian Math. Survey, 27 (1972), 85155.

[21] M. VÄTH, Voltera and Integral Equations of Vector Functions, PAM, Marcel Dekker, New York 2000. 